ГORIGINAL ARTICLE

Volume 16 Issue 22021

DOI: $10.21315 /$ aos2021.16.2.10

ARTICLE INFO

Submitted: 04/02/2021

Accepted: 09/06/2021

Online: 22/12/2021

\section{Pattern of Oral and Maxillofacial New Referrals During COVID-19 Lockdown}

\author{
Syed Nabila* Muhammad Aiman Mohd Nizarb ${ }^{\mathrm{b}}$, Muhd Fazlynizam \\ Rashdib', Szu Ching Khoo a, Muhammad Kamil Hassanc, Firdaus Hariric \\ ${ }^{a}$ Department of Oral and Maxillofacial Surgery, Faculty of Dentistry, \\ Universiti Kebangsaan Malaysia, 50300 Kuala Lumpur, Malaysia \\ ${ }^{b}$ Oral and Maxillofacial Surgery Unit, Universiti Kebangsaan Malaysia \\ Medical Center, 56000 Kuala Lumpur, Malaysia \\ 'Department of Oral and Maxillofacial Surgery, Faculty of Dentistry, \\ Universiti Malaya, 50603 Kuala Lumpur, Malaysia \\ ${ }^{\star}$ Corresponding author: syednabil@ukm.edu.my
}

To cite this article: Nabil S, Mohd Nizar MA, Rashdi MF, Khoo SC, Hassan MK, Hariri F (2021). Pattern of oral and maxillofacial new referrals during COVID-19 lockdown. Arch Orofac Sci, 16(2): 199-208. https://doi.org/10.21315/aos2021.16.2.10

To link to this article: https://doi.org/10.21315/aos2021.16.2.10

\begin{abstract}
The study aimed to quantify the impact of lockdown during the COVID-19 pandemic on new case referrals to the Oral and Maxillofacial Surgery (OMS) service. The researchers retrospectively reviewed all new referrals received during a government-imposed 47-day lockdown period and a similar period pre-lockdown as a control group. The main outcome was the differences in the number of new case referrals between the two periods. The contributing clinical and demographic factors were also explored. Appropriate bivariate statistics were computed and the level of significance was set at 0.05 for all tests. A total of 309 referrals were received during the study period. There was a reduction of new referrals due to the lockdown from five to two cases per day. There was a statistically significant reduction of cases referred from outpatient and emergency departments. There was also a statistically significant difference with regard to home address distance to the centre. Medically compromised and orofacial infection referrals were not affected by lockdown. The lockdown imposed due to the pandemic has significantly impacted the pattern of new OMS referrals. Referrals for orofacial infections, the medically compromised and inpatients were minimally affected by lockdown.
\end{abstract}

Keywords: COVID-19; lockdown; oral and maxillofacial surgery; referral

\section{INTRODUCTION}

The emergence of COVID-19 has changed the way we live. COVID-19 spreads from an infected person directly via respiratory droplets containing the virus or indirectly from contaminated inanimate objects (Centers for Disease Control and Prevention, 2020). The ease of transmission contributed to an initial uncontrollable spread causing what is now a worldwide pandemic (World
Health Organization, 2020). The difficulties in controlling the spread are compounded with the possibility of asymptomatic carriers (Rothe et al., 2020). To reduce the basic reproduction number $\left(\mathrm{R}_{0}\right)$ of the disease, governments worldwide were forced to take countermeasures to halt the rapid spread of this disease. Malaysia, as with most countries, took measures to impose lockdowns, which lasted for 47 days (Shah et al., 2020). During the lockdown period, 
the measures taken included prohibition of mass movements and gatherings, closures of all kindergartens, schools and higher education institutions and closure of nonessential government and business premises. Citizens were instructed to stay at home with only a single person within a household allowed to perform essential tasks (Malaysian National Security Council, 2020).

The changing patterns in the delivery of oral and maxillofacial surgery (OMS) clinical services during the pandemic have been reported (Maffia et al., 2020). Working mostly in the oral and facial region, OMS personnel are directly exposed to respiratory droplets and aerosols. Because of the elevated risk, early guidelines recommended elective OMS nonemergent cases to be postponed (Grant et al., 2020; Panesar et al., 2020). Focus of the OMS services were given to time-dependent diseases such as trauma and oncology contributed to the changing patterns seen (Allevi et al., 2020). The change in resources during the initial phase of the pandemic, with either OMS personnel or facilities redistribution to manage COVID-19 also contributed to the changes in the OMS services that were delivered. It was found that during the peak period of the pandemic in Italy, $17 \%$ of OMS personnel were reallocated to COVID19-related services (Allevi et al., 2020). Moreover, the enforcement of lockdowns, besides causing limited movement also indirectly instils fear and anxiety within the community (Jayakumar et al., 2020; Murphy et al., 2020). This can lead to postponement requests from the patients themselves. There have been few reports on the pattern of OMS treatment delivery in severe COVID19-affected areas. The outpatient visits were reduced by more than $87 \%$ (Allevi et al., 2020). The number of inpatient surgeries was also found to have overall reduced activity, with trauma and oncological surgery the least affected (Allevi et al., 2020; Maffia et al., 2020).
While previous reports have explored the change in the delivery of OMS services during the COVID-19 lockdowns, the pattern of new referrals during this period, to the best of our knowledge, has never been explored. The purpose of a referral system is to link primary care providers to specialised tertiary services, such as OMS. Such a system allows other healthcare providers to refer cases to these OMS units. Exploration of this aspect will enable an understanding of the demand for OMS clinical services from the perspective external to the specialty itself. It will also provide insight into the critical clinical services expected of the OMS speciality. This study aimed to explore the changes in the referral patterns following COVID-19 lockdowns.

\section{MATERIALS AND METHODS}

All new referrals to the OMS Department of the Universiti Kebangsaan Malaysia Medical Centre (UKMMC) and University Malaya Medical Centre (UMMC) during the study period were identified from the departmental clinical census. Both centres are tertiary hospitals situated in Kuala Lumpur, Malaysia. Neither of the centres are fully dedicated COVID-19 centres but still they accepted and treated a limited number of COVID-19 cases during the lockdown period. Ethical approval from both centres has been obtained from the respective ethical committees: The UKMCC (Ref. no. UKM PPI/111/8/JEP-2017-005) and UMMC (Ref. no. DF OS2031/0111[L]), prior to initiating the retrospective data collections. The data collected were all inpatient, outpatient and emergency department new referrals to the OMS specialty from 31 January until 3 May 2020. Demographic data included the age of patient, gender, race and home address. Clinical data consist of the source of referral, clinical presentations, diagnosis and treatment rendered. 
The data were then divided into two groups with a 47-day period each, namely for referral before the lockdown (31 January to 17 March 2020) and during the lockdown (18 March to 3 May 2020). Based on the home addresses, distance to the centre they were referred to was calculated using Google Maps and these data were recorded. From the clinical data, cases were categorised into type of cases based on nine main clinical services in OMS (see Table 1). Data collection was recorded in a standardised proforma and later transferred to IBM SPSS Statistics version 25 (Armonk, NY: IBM Corporation) for descriptive analyses.

\section{RESULTS}

In total, the OMS departments in the two medical centres received 309 new referrals during the study period. UKMMC received 172 while UMMC had 137 new referrals. There were more male $(58 \%)$ than female $(42 \%)$ referrals received (see Table 2). The mean age was 39.6 years old, which is not surprising as the age group of 20 to 39 was the highest contributor with $36 \%$. Referral for cases over 60 years old was also substantial at $26 \%$. The age groups of under 19 years old and 40 to 59 years old both formed $19 \%$ of the study sample. Ethnicity wise, Malay (56\%) formed the majority of the new referral cases received, followed by Chinese $(27 \%)$ and Indian $(12 \%)$. Most of the referrals accepted were from the emergency department (44\%). Outpatient and inpatient referrals made up $34 \%$ and $22 \%$ respectively of the total referrals received. On average, patients' home addresses were $65 \mathrm{~km}$ from the centres they were referred to. Most of them (61\%) lived less than $15 \mathrm{~km}$ away. Only $11 \%$ of the patients' addresses were more than $50 \mathrm{~km}$ from the medical centres. Trauma formed the major contributor for the new cases seen by OMS services, with $38 \%$. This is followed by new cases of patients who were medically compromised $(27 \%)$. Orofacial infection also formed a substantial portion of new cases $(11 \%)$, while the other type of cases formed less than $10 \%$ of the new referral seen.

When comparison was made between the two groups, there was an obvious reduction in the number of new referrals received, from 217 cases to 92 cases (Table 2). The average referrals received dropped from five to two cases per day due to the lockdown. The reduction was more substantial in UKMMC. However, the reduction of cases did not affect the proportion of cases with

Table 1 Categorisation of cases based on diagnosis

\section{Type of cases categories}

1. Oral pathology - oral soft tissue lesion; benign odontogenic jaw tumours; benign orofacial swellings; oral ulcers; Stevens-Johnson Syndrome

2. Head and neck oncology - squamous cell carcinoma; malignant salivary gland tumours

3. Cleft and craniofacial anomalies - cleft lip and palate; craniofacial syndromic cases

4. Temporomandibular disorder and orofacial pain - TMJ pain dysfunction syndrome; TMJ dislocations; internal joint derangements; trigeminal neuralgia; atypical facial pain

5. Trauma - facial bone fractures; facial soft tissue injuries; dentoalveolar injuries

6. Dentoalveolar surgery and dental implants - wisdom tooth; impacted tooth; dental implants; post-extraction bleeding

7. Orthognathic surgery - dentofacial deformities; post-orthognathic complications (bleeding, infection etc.)

8. Medically compromised - patient on antiplatelet/coagulant needing extraction; pre/post radiation dental extraction; bisphosphonate/antiangiogenic-related dental extraction; odontogenic pain in a medically compromised patient

9. Orofacial infection - odontogenic-related orofacial cellulitis or abscess involving facial spaces

Note: $T M J=$ temporomandibular joint 
regard to gender. The average age is slightly higher during the lockdown, with a mean of 42 versus 39 years old. This change in the mean age was contributed mainly by the increase in the proportion of the above 60 years age group and the reduction in the 20 to 39 years age group. Looking at the ethnicity, while Malay still formed the majority of the cases in both groups, there was a 5\% reduction during lockdown, with a similar percentage increase in the Chinese ethnicity. The most obvious change was seen in the source of referrals, with a substantial reduction of outpatient new cases from 89 cases $(41 \%)$ to only 17 cases $(19 \%)$. The absolute number of inpatient cases received actually did not differ much but formed a bigger proportion of referrals received during lockdown because of the reduction in total referrals received (see Table 2). On the other hand, emergency department referral numbers actually reduced by more than half but maintained their percentage in the total referrals received. Another major change is the reduction in the mean distance from $81 \mathrm{~km}$ to $27 \mathrm{~km}$. The reduction in mean is due to the fact that only $5 \%$ of patients lived more than $50 \mathrm{~km}$ during the lockdown

Table 2 Demographic and clinical features of cases received

\begin{tabular}{|c|c|c|c|c|c|}
\hline \multirow{4}{*}{ Variable } & & \multicolumn{2}{|c|}{ Group $N(\%)$} & \multirow{3}{*}{$\begin{array}{c}\text { Total } \\
309(100.0) \\
\end{array}$} & \multirow{4}{*}{$p$} \\
\hline & & \multirow{2}{*}{$\begin{array}{c}\text { Lockdown } \\
92(29.8) \\
\end{array}$} & \multirow{2}{*}{$\begin{array}{c}\text { No lockdown } \\
217(70.2)\end{array}$} & & \\
\hline & & & & & \\
\hline & & 2.0 cases/day & 4.6 cases/day & 3.3 cases/day & \\
\hline \multirow[t]{2}{*}{ Centre } & UKMMC & $42(45.7)$ & $130(59.9)$ & $172(55.7)$ & $0.210^{\circ}$ \\
\hline & UMMC & $50(54.3)$ & $87(40.1)$ & $137(44.3)$ & \\
\hline \multirow[t]{2}{*}{ Gender } & Female & 39 (42.4) & 91 (41.9) & $130(42.1)$ & $0.941^{\circ}$ \\
\hline & Male & $53(57.6)$ & $126(58.1)$ & $179(57.9)$ & \\
\hline \multirow[t]{5}{*}{ Age } & Mean $( \pm S D)$ & $41.6( \pm 25.0)$ & $38.8( \pm 22.5)$ & $39.6( \pm 23.3)$ & $0.655^{\circ}$ \\
\hline & $0-19$ years & $17(18.4)$ & $41(18.9)$ & $58(18.8)$ & \\
\hline & $20-39$ years & $29(31.5)$ & $82(37.8)$ & $111(35.9)$ & \\
\hline & 40-59 years & $18(19.6)$ & $41(18.9)$ & $59(19.1)$ & \\
\hline & $\geq 60$ years & $28(30.4)$ & $53(24.4)$ & $81(26.2)$ & \\
\hline \multirow[t]{4}{*}{ Ethnic } & Malay & $49(53.3)$ & $126(58.1)$ & $175(56.6)$ & $0.757^{\circ}$ \\
\hline & Chinese & $28(30.4)$ & $54(24.9)$ & $82(26.5)$ & \\
\hline & Indian & $11(12.0)$ & $29(13.2)$ & $40(12.9)$ & \\
\hline & Others & $4(4.3)$ & $8(3.7)$ & $12(3.9)$ & \\
\hline \multirow[t]{3}{*}{ Source } & Inpatient referral & $33(35.9)$ & $34(15.7)$ & $67(21.7)$ & ${ }^{*}<0.001^{\circ}$ \\
\hline & Outpatient referral & $17(18.5)$ & $89(41.0)$ & $106(34.3)$ & \\
\hline & ED referral & $42(45.7)$ & $94(43.3)$ & $136(44.0)$ & \\
\hline \multirow[t]{5}{*}{ Distance } & Mean $( \pm S D)$ & $26.9( \pm 57.8)$ & $81.3( \pm 342.2)$ & $64.9( \pm 288.8)$ & ${ }^{*} 0.027^{\beta}$ \\
\hline & $\leq 15 \mathrm{~km}$ & $53(57.6)$ & $135(62.2)$ & $188(60.8)$ & \\
\hline & $16-50 \mathrm{~km}$ & $34(37.0)$ & $51(23.5)$ & $85(27.5)$ & \\
\hline & $\geq 51 \mathrm{~km}$ & $5(5.4)$ & $28(12.9)$ & $33(10.7)$ & \\
\hline & No information & $0(0.0)$ & $3(1.4)$ & $3(1.0)$ & \\
\hline
\end{tabular}

Notes: $\alpha=$ chi-squared test, $\beta=$ Fisher's exact test. 
compared to $13 \%$ before that. The changing pattern seen in the sources of referral and distance from their home to the medical centre was statistically significant.

Regarding the types of cases seen, trauma maintained its proportion during both periods $(37 \%$ versus $38 \%)$, albeit with a reduced number of cases (34 cases versus 83 cases). However, most of the referrals received during the lockdown were for medically compromised patients with an increase to $40 \%$ from $21 \%$ prior lockdown (see Table 3). Orofacial infection was also a significant contributor of new referrals seen in both periods. It is not surprising to see no new cases in the categories of "orthognathic surgery" and "dentoalveolar surgery and implants" during the lockdown, but it is also notable that no new "head and neck oncology" and "oral pathology" cases were received. Looking in more detail at the types of cases seen, medically compromised cases were the main contributor of new inpatient referrals received pre- and during lockdown (see Table 3). Comparing both periods, the types of cases for inpatient referrals received were similar, with only the proportion of each categories altered. The common referrals for inpatients were "medically compromised," "orofacial infection," "cleft and craniofacial anomalies" and "trauma." Similarly, medically compromised referrals were the main bulk of outpatient referrals for both periods. However, the number of outpatient referrals for medically compromised patients during lockdown were reduced to half from the usual number received prelockdown. Adding this to the total absence of any referrals from other categories except orofacial infection, the number of outpatient referrals received was one quarter of the

Table 3 Source of referral for the different types of cases

\begin{tabular}{|c|c|c|c|c|c|}
\hline & Type of cases & Inpatient & Outpatient & Emergency & Total \\
\hline \multirow[t]{10}{*}{ Lockdown } & Oral pathology & $0(0.0)$ & $0(0.0)$ & $0(0.0)$ & $0(0.0)$ \\
\hline & Head and neck oncology & $0(0.0)$ & $0(0.0)$ & $0(0.0)$ & $0(0.0)$ \\
\hline & Cleft and craniofacial anomalies & $3(9.1)$ & $0(0.0)$ & $0(0.0)$ & $3(3.3)$ \\
\hline & TMJ disorder and orofacial pain & $0(0.0)$ & $0(0.0)$ & $1(2.4)$ & $1(1.1)$ \\
\hline & Trauma & $2(6.1)$ & $0(0.0)$ & $32(76.2)$ & $34(37.0)$ \\
\hline & $\begin{array}{l}\text { Dentoalveolar surgery and } \\
\text { dental implants }\end{array}$ & $0(0.0)$ & $0(0.0)$ & $0(0.0)$ & $0(0.0)$ \\
\hline & Orthognathic surgery & $0(0.0)$ & $0(0.0)$ & $0(0.0)$ & $0(0.0)$ \\
\hline & Medically compromised & $21(63.6)$ & $14(82.4)$ & $2(4.8)$ & $37(40.2)$ \\
\hline & Orofacial infection & $7(21.2)$ & $3(17.6)$ & $7(16.7)$ & $17(18.5)$ \\
\hline & Total & $33(100.0)$ & $17(100.0)$ & $42(100.0)$ & $92(100.0)$ \\
\hline \multirow[t]{10}{*}{ No lockdown } & Oral pathology & $1(2.9)$ & $13(14.6)$ & $2(2.1)$ & $16(7.4)$ \\
\hline & Head and neck oncology & $0(0.0)$ & $5(5.6)$ & $0(0.0)$ & $5(2.3)$ \\
\hline & Cleft and craniofacial anomalies & $8(23.5)$ & $5(5.6)$ & $1(1.1)$ & $14(6.5)$ \\
\hline & TMJ disorder and orofacial pain & $0(0.0)$ & $8(9.0)$ & $1(1.1)$ & $9(4.1)$ \\
\hline & Trauma & $4(11.8)$ & $1(1.1)$ & $78(83.0)$ & $83(38.2)$ \\
\hline & $\begin{array}{l}\text { Dentoalveolar surgery and } \\
\text { dental implants }\end{array}$ & $0(0.0)$ & $18(20.2)$ & $2(2.1)$ & $20(9.2)$ \\
\hline & Orthognathic surgery & $0(0.0)$ & $6(6.7)$ & $1(1.1)$ & $7(3.2)$ \\
\hline & Medically compromised & $15(44.1)$ & $29(32.6)$ & $1(1.1)$ & $45(20.7)$ \\
\hline & Orofacial infection & $6(17.7)$ & $4(4.5)$ & $8(8.5)$ & $18(8.3)$ \\
\hline & Total & $34(100.0)$ & $89(100.0)$ & $94(100.0)$ & $217(100.0)$ \\
\hline
\end{tabular}


pre-lockdown numbers. Trauma, meanwhile, forms the majority of referrals received from the emergency unit during both periods. After trauma, orofacial infection is the next most common case received by the emergency unit. The number of trauma referrals halved during the lockdowns, but orofacial infection numbers remained static.

\section{DISCUSSION}

Lockdown measures' main aim is to slow down the rapid spread of disease transmission. By flattening the curve, it was hoped that the time bought by this measure would prevent the health service from being overwhelmed and eventually reduce overall mortality. It has shown to be effective in reducing the $\mathrm{R}_{0}$ of the disease (Flaxman et al., 2020). Similarly, we saw a reduction of cases in Malaysia following strict lockdown measures (Tang, 2020). However, these measures are not without ramifications. They have caused a widespread social and economic impact (Nicola et al., 2020). More pertinently is the impact on the healthcare delivery system and specifically on the delivery of OMS services. Previous surveys have reported the changes in the delivery patterns of OMS services during lockdowns (Allevi et al., 2020; Maffia et al., 2020). This study adds further understanding in this regard by assessing the demands of OMS services during these COVID-19 lockdowns from its starting point, which is new case referrals.

Several recommendations have been made regarding prioritising cases during the COVID-19 pandemic (Chigurupati et al., 2020; Grant et al., 2020; Panesar et al., 2020; Zimmermann \& Nkenke, 2020). These guidelines generally suggest postponement of all elective nonemergency cases. In OMS, it is accepted that oncology, trauma and severe orofacial infection constitute cases that should continue (Panesar et al., 2020; Zimmermann \& Nkenke, 2020). Because surgical scheduling is within the autonomy of the OMS unit itself, these recommendations can be adhered to. Prioritising surgery will come with the later consequences of increasing case load and burden of disease (Brindle et al., 2020). The approach in handling new referrals is much less discussed. Referrals come from sources external to the OMS units, thus coordinating them is less straightforward. This study found that there was a substantial drop in the new case referrals during the lockdown. Previous studies in other surgical disciplines assessing the referral pattern, similarly, found a significant drop in the number of new cases (Jayakumar et al., 2020; Murphy et al., 2020). However, the reduction of new cases should not be assumed to be equal to a reduction of the incidence of new disease but instead it might indicate that patients with symptoms were avoiding treatment during this period (Jayakumar et al., 2020). Thus, similarly, to delaying elective surgery, this will only cause a further backlog that might overwhelm the OMS services later on.

Even with the reduction of new referrals received during lockdowns, the gender representation did not change. There was, however, a slight increase in the mean age of patients. This is likely to be due to a reduction in trauma cases during the lockdown, which are known to be more common in younger age groups (Hussaini et al., 2007). Studies have shown that the positive side of lockdowns is that they reduce the incidence of trauma-related injuries, mainly due to a reduction in road traffic (Jayakumar et al., 2020; Murphy et al., 2020). This study also found a reduction in the proportion of Malay ethnicity during the lockdown. This trend is probably due to similar reasons with the changes seen relating to age, as previous studies in Malaysia have shown that trauma-related injuries are more prevalent among Malays (Hussaini et al., 2007).

The centres included in this study are tertiary referral hospitals located in Kuala Lumpur and accept referrals from across the nation. The distance a patient needs to travel to a hospital depends on local factors, including 
the location of the healthcare facilities, the healthcare delivery system, geographical accessibility and transport infrastructure, among others. A previous study in the UK stated $89 \%$ of patients needed to travel less than 6 miles $(9.7 \mathrm{~km})$ to the referred OMS centre (Coulthard et al., 2000a). In comparison, the distance the patients in this study expected to travel appear to be higher, probably due to the local factors stated above. Taking this into consideration, the exact distances of travel in this study may not be applicable to other localities. However, the statistically significant finding regarding the reduction of distance during lockdown is relevant regardless of locality. What this suggests is that restrictions during lockdown reduced the accessibility of patients living further away from accessing OMS services. A previous study has shown that household wealth is inversely related with traveling time to the city (Weiss et al., 2018). Therefore, the lockdown increased the socioeconomic inequality gap specifically in accessing OMS services. The use of technology, such as telemedicine, should be considered as a solution to alleviate issues relating to the movement restrictions (Coulthard et al., 2000a; Chigurupati et al., 2020).

The scope of work for each OMS unit may differ slightly, depending on the facility and subspecialisation expertise of their personnel. These factors may affect the type of cases seen in a particular OMS unit. This study reduces that variability by including two centres. The core area of expertise of OMS, however, should be the same anywhere that includes traumatology, dentoalveolar surgery, dental implants and oral/jaw pathologies (Laskin, 2008). Being a tertiary referral hospital, both centres also accept complex surgical cases such as orthognathic surgery, oncology, cleft and craniofacial surgery. This study found that there in reduced numbers of new case referral in all type of cases except for orofacial infection. Our findings are in agreement with a recent study that similarly found no difference in the percentage of OMS consultation for orofacial infection during the peak of COVID-19 pandemic in the US (Johnson et al., 2020). As most orofacial infections present acutely and are associated with pain, it is unlikely that patients delay seeking treatment. Another important finding is that trauma cases halved during lockdown due to reduced traffic, as discussed earlier (Jayakumar et al., 2020; Murphy et al., 2020). Of grave concern, however, is the absence of any new head and neck oncology referrals during the lockdown. A similar reduction was seen in neuro-oncological referrals (Jayakumar et al., 2020). It is possible there was an avoidance by the patients to present themselves during this period (Jayakumar et al., 2020). The absence of symptoms, such as in the early stages of oral cancer, may possibly contribute to the delay in seeking treatment during the lockdown period. The ramification of this finding is serious since late presentation of oncological cases will affect prognosis. The definitive evidence of this scenario can only be ascertained by assessing the staging of oncological cases presented following lockdown, which is out of the scope of this study.

Referral of a case can come from various sources. Outpatient new cases would usually come from the general dental practitioner needing specialist management for their patients. Meanwhile, inpatient referrals would come from medical colleagues of other specialties needing OMS input for patients under their care. Emergency department referrals would commonly indicate urgent need of care from the patients themselves, with emergency physicians being mediators to convey their needs via referrals. As found from this study, the reduction in the number of referrals to OMS during lockdown was substantial. Interestingly, the reduction in new referrals was only attributed to the reduction of outpatient and emergency cases. Inpatient referrals were consistent throughout both periods. More than $85 \%$ of inpatient referrals received during both periods were from the "medically compromised," "orofacial infection" and "cleft and craniofacial anomalies" categories. This study highlights an aspect of OMS 
service that is often overlooked. Being a hospital-based specialty with training in dentistry creates an expectation of services from other specialities that are not affected by the lockdown. This shows that OMS services are recognised as an integral interdisciplinary member in the management of patients with complex diseases. Outpatient referrals saw a significant drop in the number of referrals. It was previously reported that the most common reasons for outpatient referral were the anticipated difficulty of surgery and patients who were medically compromised (Coulthard et al., 2000b) Dental practitioners' understanding of the cases that should be delayed is reflected in the changing pattern of outpatient referrals seen. The absence of all categories except for "medically compromised" and "orofacial infection" in outpatient referrals during lockdown further reaffirms the critical demand of these categories of cases. The reduction in referrals from the emergency departments meanwhile can be explained by the reduction in trauma cases during lockdown, which is the main contributor of OMS referrals from the emergency units.

There are a few limitations of this study. To increase applicability of these findings, we included two different centres in a hope to reduce centre-to-centre variability. However, because it is still based on a single-country situation, the variability of cases seen might be different when compared to other nations. Still, most of the changing trend seen here can be extrapolated to a certain degree. Secondly, in interpreting the results of this study, consideration should be made on the differences in the strictness of the lockdowns imposed by different governments. The lockdown imposed for 47 days in Malaysia was stringent and contributed to the findings seen.

\section{CONCLUSION}

The lockdown imposed due to the pandemic has significantly impacted the patterns of new OMS referrals. The reduction in the number of new referrals was not only contributed to by the reduction in the incidence of trauma, but also to the reduction of almost all types of new referrals, including for malignant conditions. The demand for the management of orofacial infection and medically compromised patients are the only conditions unaffected by lockdown. Similarly, inpatient referrals were unaffected. It is highly likely that the pandemic and lockdown causes treatment-seeking delay. Future studies should investigate the consequences of lockdowns on the number of new cases and the severity of diseases postlockdown. Results from this study provide a better understanding of what to expect in any future local or global catastrophic event that causes restriction in movement. This hopefully will allow better planning of resources in such a situation.

\section{ACKNOWLEDGEMENTS}

The authors would like to thank Mrs. Nur Sulwana Mohamad Hanapi, who contributed to the statistical analysis in this study.

\section{REFERENCES}

Allevi F, Dionisio A, Baciliero U, Balercia P, Beltramini GA, Bertossi D et al. (2020). Impact of COVID-19 epidemic on maxillofacial surgery in Italy. $\mathrm{Br} \mathcal{F}$ Oral Maxillofac Surg, 58(6): 692-697. https://doi .org/10.1016/j.bjoms.2020.04.035

Brindle ME, Doherty G, Lillemoe K, Gawande A (2020). Approaching surgical triage during the COVID-19 pandemic. Ann Surg, 272(2): e40-e42. https://doi.org/10.1097/ SLA.0000000000003992

Centers for Disease Control and Prevention (2020). How COVID-19 spreads. Retrieved 10 January 2021, from https://www.cdc .gov/coronavirus/2019-ncov/prevent-getting -sick/how-covid-spreads.html 
Chigurupati R, Panchal N, Henry AM, Batal $\mathrm{H}$, Sethi A, D'innocenzo R et al. (2020). Considerations for oral and maxillofacial surgeons in COVID-19 era: Can we sustain the solutions to keep our patients and healthcare personnel safe? F Oral Maxillofac Surg, 78 (8): 1241-1256. https://doi.org/10 $.1016 /$ j.joms.2020.05.027

Coulthard P, Kazakou I, Koran R, Worthington HV (2000a). Referral patterns and the referral system for oral surgery care. Part 2: The referral system and telemedicine. Br Dent F, 188(7): 388-391. https://doi.org/ 10.1038/sj.bdj.4800491

Coulthard P, Kazakou I, Koron R, Worthington HV (2000b). Referral patterns and the referral system for oral surgery care. Part 1: General dental practitioner referral patterns. $\mathrm{Br}$ Dent $\mathcal{F}, \mathbf{1 8 8}(3)$ : 142-145. https://doi.org/10.1038/sj.bdj.4800415

Flaxman S, Mishra S, Gandy A, Unwin HJT, Mellan TA, Coupland $\mathrm{H}$ et al. (2020). Estimating the effects of non-pharmaceutical interventions on COVID-19 in Europe. Nature, 584(7820): 257-261. https://doi.org/10.1038/s41586 $-020-2405-7$

Grant M, Buchbinder D, Dodson TB, Fusetti S, Leung MYY, Aniceto GS et al. (2020). AO CMF International Task Force recommendations on best practices for maxillofacial procedures during COVID-19 pandemic. Craniomaxillofac Trauma Reconstr, 13(3): 151-156. https://doi.org/10 $.1177 / 1943387520948826$

Hussaini HM, Rahman NA, Rahman RA, Nor GM, AI Idrus SM, Ramli R (2007). Maxillofacial trauma with emphasis on soft-tissue injuries in Malaysia. Int $\mathcal{F}$ Oral Maxillofac Surg, 36(9): 797-801. https://doi .org/10.1016/j.ijom.2007.04.004
Jayakumar N, Kennion O, Villabona AR, Paranathala M, Holliman D (2020). Neurosurgical referral patterns during the coronavirus disease 2019 pandemic: A United Kingdom experience. World Neurosurg, 144: e414-e420. https://doi.org/ 10.1016/j.wneu.2020.08.162

Johnson RE 3rd, Foy TE, Ellingsen TA, Nelson JL, Dillon JK (2020). Odontogenic infections: Disease burden during COVID-19 at a single institution. F Oral Maxillofac Surg, 79(4): 830-835. https://doi .org/10.1016/j.joms.2020.10.015

Laskin DM (2008). The past, present, and future of oral and maxillofacial surgery. $\mathcal{F}$ Oral Maxillofac Surg, 66(5): 1037-1040. https://doi.org/10.1016/j.joms.2007.11.037

Maffia F, Fontanari M, Vellone V, Cascone P, Mercuri LG (2020). Impact of COVID-19 on maxillofacial surgery practice: A worldwide survey. Int $\mathcal{F}$ Oral Maxillofac Surg, 49(6): 827-835. https://doi.org/10 .1016/j.ijom.2020.04.015

Malaysian National Security Council (2020). COVID-19 Movement Control Order. Retrieved 10 January 2021, from https://asset.mkn.gov.my/web/wp-content/ uploads/sites/3/2020/03/PERGERAKAN - KA W A LAN - C OVID 19 - a m e n d ed -18032020-UPDATED-12.12AM.pdf

Murphy T, Akehurst H, Mutimer J (2020). Impact of the 2020 COVID-19 pandemic on the workload of the orthopaedic service in a busy UK district general hospital. Injury, 51(10): 2142-2147. https://doi.org/ 10.1016/j.injury.2020.07.001

Nicola M, Alsafi Z, Sohrabi C, Kerwan A, AlJabir A, Iosifidis C et al. (2020). The socio-economic implications of the coronavirus pandemic (COVID-19): A review. Int $\mathcal{f}$ Surg, 78: 185-193. https://doi.org/10.1016/j.ijsu.2020.04.018 
Panesar K, Dodson T, Lynch J, Bryson-Cahn C, Chew L, Dillon J (2020). Evolution of COVID-19 guidelines for University of Washington oral and maxillofacial surgery patient care. F Oral Maxillofac Surg, 78(7): 1136-1146. https://doi.org/10.1016/j.joms .2020 .04 .034

Rothe C, Schunk M, Sothmann P, Bretzel G, Froeschl G, Wallrauch C et al. (2020). Transmission of 2019-nCoV infection from an asymptomatic contact in Germany. $N$ Engl f Med, 382(10): 970-971. https://doi. org/10.1056/NEJMc2001468

Shah AUM, Safri SNA, Thevadas R, Noordin NK, Rahman AA, Sekawi Z et al. (2020). COVID-19 outbreak in Malaysia: Actions taken by the Malaysian government. Int F Infect Dis, 97: 108-116. https://doi.org/ 10.1016/j.ijid.2020.05.093

Tang KHD (2020). Movement control as an effective measure against COVID-19 spread in Malaysia: An overview. $Z$ Gesundh Wiss, Published online 13 June 2020. https://doi.org/10.1007/s10389-020 $-01316-w$
Weiss DJ, Nelson A, Gibson HS, Temperley W, Peedell S, Lieber A et al. (2018). A global map of travel time to cities to assess inequalities in accessibility in 2015. Nature, 553(7688): 333-336. https://doi.org/10 .1038 /nature25181

World Health Organization (2020). WHO director-general's opening remarks at the media briefing on COVID-19. Retrieved 10 January 2021, from https://www.who.int/ $\mathrm{dg} /$ speeches/detail/who-director-general-s -opening-remarks-at-the-media-briefing -on-covid-19---16-march-2020

Zimmermann M, Nkenke E (2020). Approaches to the management of patients in oral and maxillofacial surgery during COVID-19 pandemic. I Craniomaxillofac Surg, 48(5): 521-526. https://doi.org/10.1016/j.jcms .2020 .03 .011 